\title{
Investigation on heat transfer characteristics of roughened solar air heater using ANN technique
}

\author{
Harish K. Ghritlahre*, Radha K. Prasad \\ Department of Mechanical Engineering, National Institute of Technology, Jamshedpur, Jharkhand, 831014, India
}

Corresponding Author Email: harish.ghritlahre@gmail.com

https://doi.org/10.18280/ijht.360114

Received: 24 October 2017

Accepted: 16 January 2018

\section{Keywords:}

solar air heater, artificial neural network, levenberg-marquardt learning algorithm, nusselt number, heat transfer

\begin{abstract}
In present work, Artificial Neural Network (ANN) model has been developed to predict the heat transfer from roughened absorber plate to air passing through the ducts of solar air heater and compared with actual experimental data. Two different types of SAH ducts with roughened absorber plate at single side in one and three sides absorber plates in the other, have been taken up for the analysis of heat transfer. The data for analysis have been collected by conducting actual experiments on the SAHs. ANN model has been structured with five input parameters such as number of rough surface sides, relative roughness height, relative roughness pitch, roughness size and Reynolds Number in input layer, and Nusselt number in output layer. Levenberg-Marquardt (LM) algorithm with feed-forward back propagation is used in present model. The LM learning algorithms with 10 neurons in hidden layer has been found as optimal on the basis of statistical error analysis. The predicted value of heat transfer of solar air heater with highest $\mathrm{R}^{2}$ value gives satisfactory results. The values of RMSE, MAE and $\mathrm{R}^{2}$ were found $0.892025,0.66261$ and 0.99532 respectively during training stage. Similarly, for testing stage these values were 0.55094 , 0.3168 and 0.9979 respectively. The statistical results show that the proposed MLP ANN model successfully predicts the heat transfer analysis of roughened solar air heater.
\end{abstract}

\section{INTRODUCTION}

Energy plays an important role in economic growth of a nation. The fossil fuels are limited on the earth. In view of the consumption of fossil fuels at a faster rate, it is necessary to develop efficient systems based on alternative sources of energy. Of the several types of renewable energy available on the earth, the solar energy is one of the most abundant and clean source. There are two ways of solar energy utilization: active and passive. In passive solar energy utilization sun rays are directly used without the aid of any equipment, but in active way sun rays are not directly used but some kind of mechanical equipment are needed to convert the solar energy into other forms of energy. Solar air heater comes in the category of active solar energy utilization systems.

In the solar air heating collector, absorber plate is main component which collects the solar energy in the form of heat and transfers this energy to flowing air. Due to low heat capacity and low thermal conductivity of flowing air, the convective heat transfer coefficient between absorber plate and the air is low, and hence the major issue to increase the value of heat transfer coefficient and thereby the heat transfer rate. This objective can be achieved by using extended surfaces on the absorber plate on air flow side [1, 2], artificial roughness on air flow side [3-9], and porous heat absorbing materials in the air flow duct.

The experimental study as well as the analytical study followed by the computational techniques, requires a lot of time to arrive at an accurate result due to extensive computer codes that lead to huge programming algorithms especially when the solution of complex differential equations are involved. The use of Artificial Neural Networks (ANN) technique, on the other hand, saves time and also provides key information patterns in a multi-dimensional information domain and, therefore, this technique has been becoming increasingly popular in Science and Engineering, especially in Thermal Engineering applications in recent years. Many researchers have used ANN in the past:

Kalogirou [10] used neural network in renewable energy systems to predict solar radiation, wind speed and also used for load forecasting of PV and building service systems. Facao et al. [11] constructed two different types of NN model by use of MLP and RBF, and predicted the collector efficiency and useful heat gain of plate and tube type heat pipe hybrid solar collector. They also found that MLP model performed slightly better than RBFs model.

Islamoglu et al. [12] applied neural technique to predict the heat transfer analysis of corrugated channel. They conducted experiments and collected data for ANN modeling. They found the results of predicted data with actual experimental data less than 4\% error of MAE. Kalogirou [13] predicted the performance parameters of flat plate collector using neural network. For predicting the parameters six different types of ANN model were constructed on the basis of measuring experimental data and predicted with satisfactory results. Sozen et al. [14] conducted experiments on flat plate solar air heater and calculated the thermal efficiency. By the use of experimental and calculated data optimal ANN was constructed using seven parameters in input layer, twenty neurons with two hidden layers and one neuron used in output layer and predicted the thermal efficiency with satisfactory results. Akdag et al. [15] structured ANN model to predict the heat transfer in oscillating annular flow. They found the predicted results with less than $5 \%$ error. Caner et 
al. [17] used neural network tool for estimating the thermal efficiency of solar air collector. For evaluating the thermal efficiency, experiments were performed with two types of zigzagged absorber plate in solar air heater and collected the data for five days for constructing ANN model designed on the LM learning algorithm in nftool tool module in MATLAB. They found on the basis of stastiscal error analysis the predicted thermal efficiency ANN model was proved reliable and accurate. Benli [18] initiated ANN technique for determining the thermal efficiency of two different types of solar air heater with trapeze and corrugated shaped absorber plate. For estimating the collector efficiency experiments were performed and collected data for modeling of ANN model with LM learning algorithms. Finally, predicted results were found with LM-3 neurons in hidden layer for successfully and accurate thermal performance of solar air collector. Akdag et al.[19] applied ANN method to predict heat transfer from a flat plate subjected to a transversely pulsating jet using optimal neural model. They also found that the ANN predictions errors were less than $1 \%$. Azizi et al. [20] developed ANN model for estimating the heat transfer coefficient during condensation of R134a in inclined tubes. The predicted results with values of MAPE and $\mathrm{R}$ were $1.61 \%$ and 0.9963 respectively. Ghritlahre and Prasad [21] used ANN to estimate the performance of porous bed solar air heater using optimal training function.

From the above literature, it is found that ANN model has been used only for predicting the performance of various thermal systems; therefore, it is being used for first time in the present study for predicting heat transfer characteristics of solar air heater also. In present work, total fifty sample data sets are used which are obtained from experiments for two different types of roughened absorber plate. The optimal ANN model has been found by stastiscal error analysis of training stage. The proposed MLP ANN model predicted results have been compared with actual experimental data.

\section{EXPERIMENTAL STUDY AND DATA COLLECTION}

The schematic diagram of experimental setup is shown in Figure 1. The setup has been designed and fabricated with two ducts $\mathrm{A}$ and $\mathrm{B}$ as shown in Figure 1. In duct B, three sided roughened absorber plate has been used each covered with transparent glasses cover. In duct A, a single roughened absorber plate with a glass cover at the top. The photographic view of setup is shown in Figure 2, and the absorber plate's photographic view is shown in Figure 3. Experiments have been performed at NIT Jamshedpur, India. The rectangular duct dimension is $2000 \mathrm{~mm} \times 200 \mathrm{~mm} \times 25 \mathrm{~mm}$, in which the test section is of $1500 \mathrm{~mm}$ length. The duct is connected with flow pipe with an orifice meter fitted to it. Two U-tube manometers have been used. For measuring the temperature of air 6 digital thermometers were used in each duct. For measurement of plate temperature copper- constantan 28 SWG thermocouples have been used. The experiments were conducted for a range of Reynold number (Re) 5000-13000. The relative roughness pitch range $(\mathrm{P} / \mathrm{e})$ is $10-20$ and relative roughness height (e/D) is 0.0315-0.0247 [9]. The mass flow of air is controlled by autovariac.

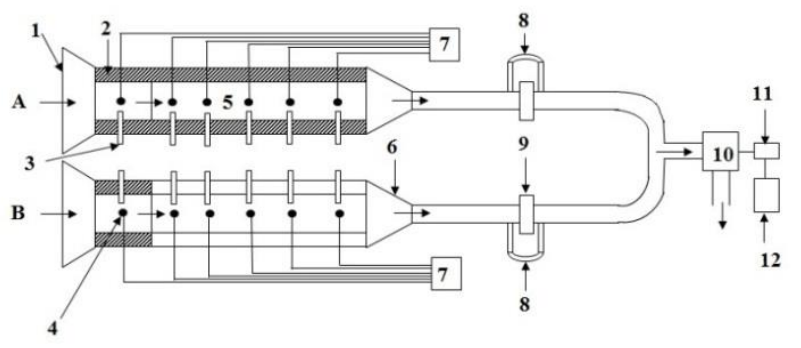

Figure 1. Detail schematic diagram of experimental setup [9]

A. One sided roughened absorber plate duct

B. Three-sided roughened absorber plate duct

1. Entry section

2. Insulation

3. Digital thermometer

4. Thermocouple probe

5. Test section

6. Diverging section

7. Selector switch

8. U tube manometer

9. Orifice meter

10. Blower

11. Electric motor

12. Auto variac

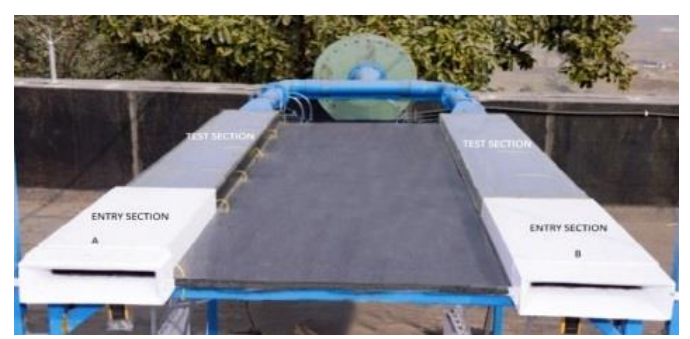

Figure 2. Photographic view of experimental setup [9].

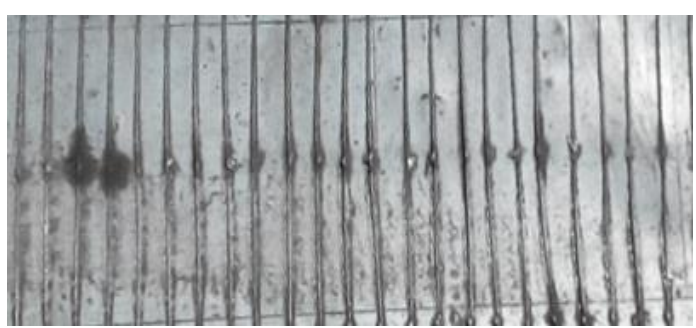

(a)

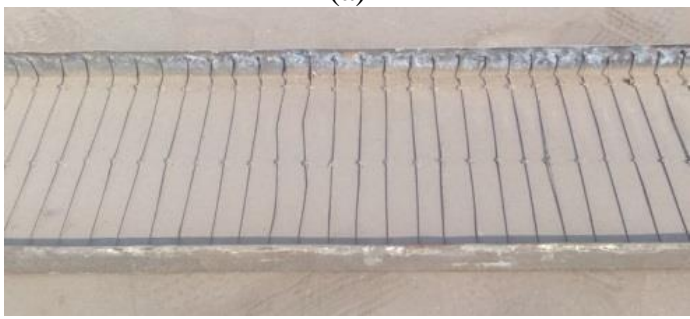

(b)

Figure 3. Absorber plate photographic view (a) Single side rough (b) Three side rough 


\section{HEAT TRANSFER CALCULATION OF SOLAR AIR HEATER}

At Steady state condition, the values of flowing air and absorber plate temperatures at various sections in the duct were used to determine the values of different parameters. Mass flow rate of air $m_{f}$ is calculated with pressure drop, using following formula [16]:

$m_{f}=C_{d} A_{o}\left[\frac{2 \rho_{a}(\Delta P)_{a}}{1-\beta^{4}}\right]^{0.5}$

The experimental value of useful heat gain of air is calculated by the following expression:

$Q_{u}=m_{f} C_{p}\left(T_{f o}-T_{f i}\right)$

where $T_{f o}$ and $T_{f i}$ are outlet and inlet air temperatures respectively.

The heat transfer coefficient $\mathrm{h}$, between plate and air is determined as:

$$
h=\frac{Q_{u}}{A\left(\overline{T_{p}}-\overline{T_{f}}\right)}
$$

where $\mathrm{A}$ is collector area, $T_{p}$ is average plate temperature and $T_{f}$ is average air temperature.

The Nusselt number is calculated by following formula:

$$
N u=\frac{h D_{h}}{k}
$$

where $D_{h}$ is hydraulic diameter and $\mathrm{k}$ is thermal conductivity of air.

\section{ARTIFICIAL NEURAL NETWORKS}

Artificial Neural Networks are used to solve any complicated problem of different area such as forecasting, control systems, optimization and decision making in fields of Engineering and management [10].

ANN is computational technique in MATLAB which works like a human brain. It is a complex information processing system, which is structured from interconnected segmental processing elements called as neurons. These neurons find the input information from other sources and then perform generally a non-linear operation on the result and then give final results as output. ANN works in two ways, first learning and then storing the knowledge in interconnects called weights. ANN is a simulation tool in MATLAB which can be used to estimate the values on the basis of input parameters, optimum topology and training processes. An ANN model consists of three layers: First input layer, last output layer and in middle hidden layer. In feed forward networks (Figure 4), each product of input elements $\left(a_{i}\right)$ and weights $\left(w_{i j}\right)$ are fed to summing junctions and is summed with bias $\left(b_{j}\right)$ of neurons as follows [22]:

$$
X=\left(\sum_{i=1}^{n} w_{i j} a_{i}\right)+b_{j}
$$

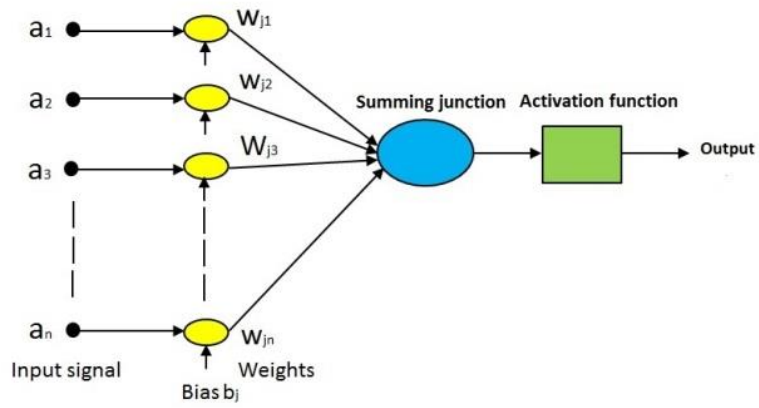

Figure 4. General structure of artificial neurons

Then this sum $\mathrm{X}$ passes through transfer function $F$ which generates an output.

$$
F(X)=u_{j}=F\left[\left(\sum_{i=1}^{n} w_{i j} a_{i}\right)+b_{j}\right]
$$

Tansig and logsig are most commonly used transfer functions in hidden layer. The nonlinear activation function which is widely used is called as sigmoid function whose output lies in the mid of 0 and 1, and the sigmoid transfer function is written as:

$F(X)=\frac{1}{1+e^{-X}}$

If the values of input and output layers are negative, then tansig transfer function is used.

$$
F(X)=\frac{e^{X}-e^{-X}}{e^{X}+e^{-X}}
$$

During training period, training algorithm adjusts the weights and biases iteratively to minimize the error between actual and predicted values of ANN model. A set of input and output data, which are loaded in the network as inputs is called as training set of data. The input data sets are trained by learning algorithms. This training process is repeated until the error reduces to an acceptable value.

The mostly used learning algorithms are SCG, CGP, BFG and LM, in which LM learning algorithms are faster than other learning algorithms.

\section{PERFORMANCE CRITERIA OF MODEL}

The optimal ANN model, applied to predict the heat transfer, is based on the criteria of minimum errors of RMSE and best fit of ANN predicted data with experimental data on the basis of correlation coefficient $\mathrm{R}$.

Root mean square error: 


$$
R M S E=\sqrt{\frac{1}{n} \sum_{i=1}^{n}\left(X_{A, i}-X_{P, i}\right)^{2}}
$$

Correlation coefficient:

$$
R=\frac{\sum_{i=1}^{n}\left(X_{P, i}-\bar{X}_{P}\right)\left(X_{A, i}-\bar{X}_{A}\right)}{\sqrt{\sum_{i=1}^{n}\left(X_{P, i}-\bar{X}_{p}\right)^{2}\left(X_{A, i}-\bar{X}_{A}\right)^{2}}}
$$

\section{RESULTS AND DISCUSSION}

\subsection{Validity test of experimental study}

The experimental values of Nusselt number obtained for one side and three sides roughened solar air heaters has been compared with one side roughened (Prasad, 2013) and three sides roughened (Prasad et. al, 2014) solar air heater ducts respectively.

The comparison of experimental and estimated values of Nusselt number of three sides and one side is shown in Fig. $5 \mathrm{a}$ and $5 \mathrm{~b}$ respectively. The mean absolute deviation of the experimental values of Nusselt number and from those predicted by using the correlations of Prasad et. al (2014) and Prasad (2013), are $\pm 3.831 \%$ and $\pm 3.825 \%$ for one side and for three sides roughened absorber plates respectively. From the Fig. 5a and Fig. 5b, a good agreement between experimental and predicted values is observed, which ensures the accuracy of the data taken up in the present experimental investigation.

\subsection{Parametric study}

The values of Nusselt number were calculated for the range of flow parameters investigated for one side and for three sides roughened solar air heater ducts [9]. Fig. 6 and 7 show the effect of the roughness and flow parameter on the value of the average Nusselt number of one side and three sides roughened ducts based on th roughness parameters $P / e$ and $e / D$ respectively.

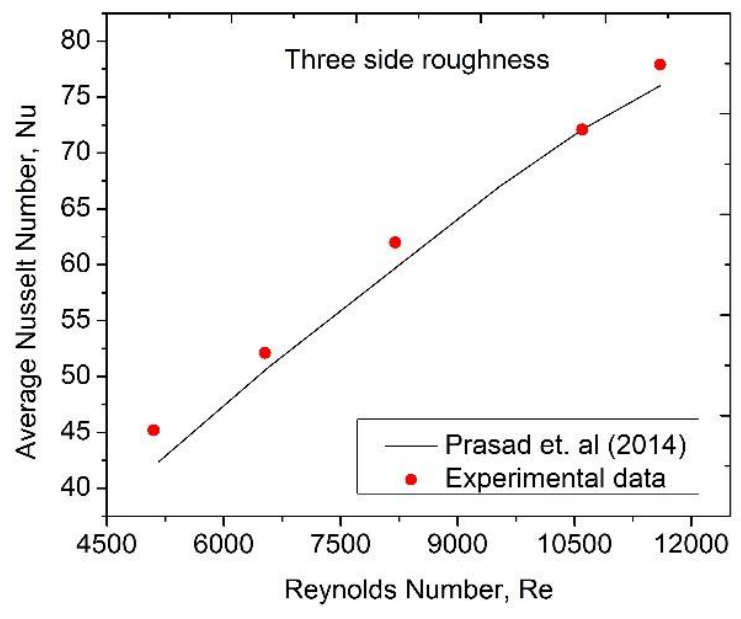

(a)

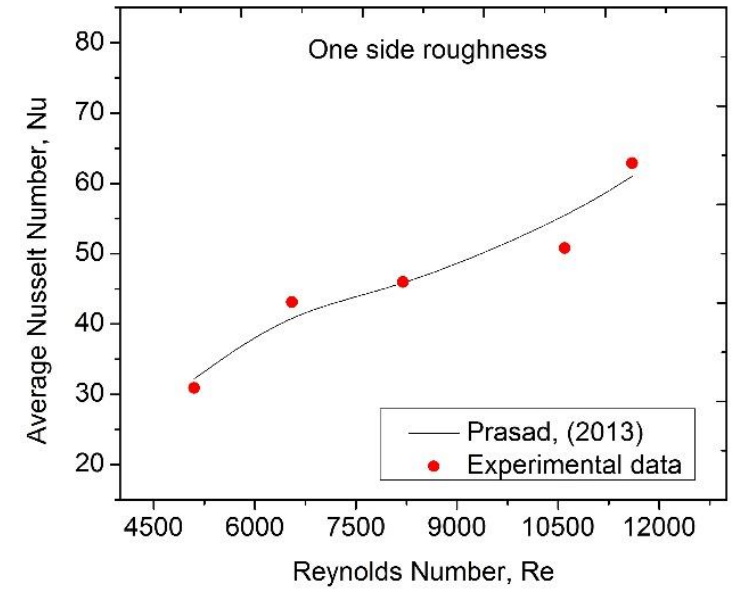

(b)

Figure 5. Comparison of heat transfer (a) Three side rough (b) One side rough, at $\mathrm{P} / \mathrm{e}=10, \mathrm{e} / \mathrm{D}=0.0247$

\section{a. Variation of $\mathrm{Nu}$ with $\mathrm{Re}$}

The effect of Reynold's number $R e$ on average Nusselt number $N u$ for constant value of $P / e$ and $e / D$ have been shown in Fig. 6 and 7 respectively for one side and three sides roughened ducts. From these Figs. it is observed that the average Nusselt number increases with decrease in $P / e$ or increase in $e / D$ with increase in Reynold's number $R e$.

\section{b. Effect of P/e on $\mathbf{N u}$}

From Fig. 6, it has been found that the average Nusselt number decreases with increase in $\mathrm{P} / \mathrm{e}$. The maximum average $N u$ corresponding to $\mathrm{P} / \mathrm{e}=10$ for both cases of one side and three sides roughened ducts has been found.

\section{c. Effect of e/D on $\mathbf{N u}$}

From Fig. 7, it has been found that the average Nusselt number increases with increase in $\mathrm{e} / \mathrm{D}$ and it is maximum at $\mathrm{e} / \mathrm{D}=0.0247$ for one side and three sides roughened ducts.

The values of Nusselt number for three sides roughened collector enhance by an amount of $21-78 \%$ over those of for one side roughened collector.

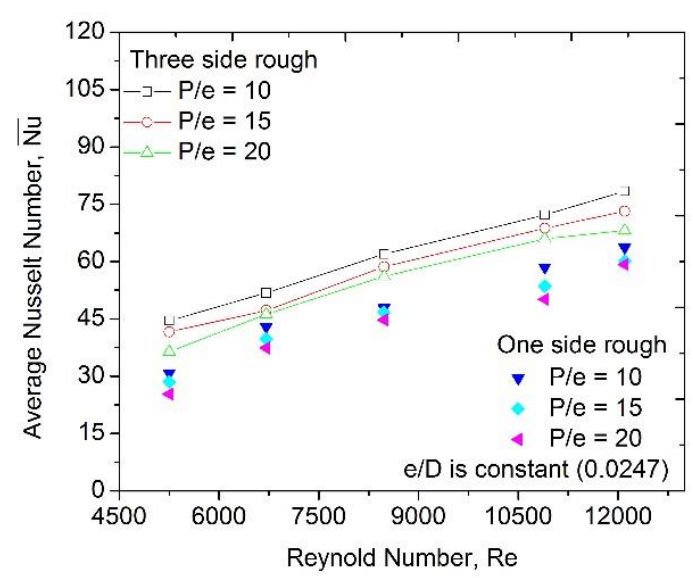

Figure 6. Variation of Nusselt number with Reynold's number for different values of $\mathrm{p} / \mathrm{e}$. 


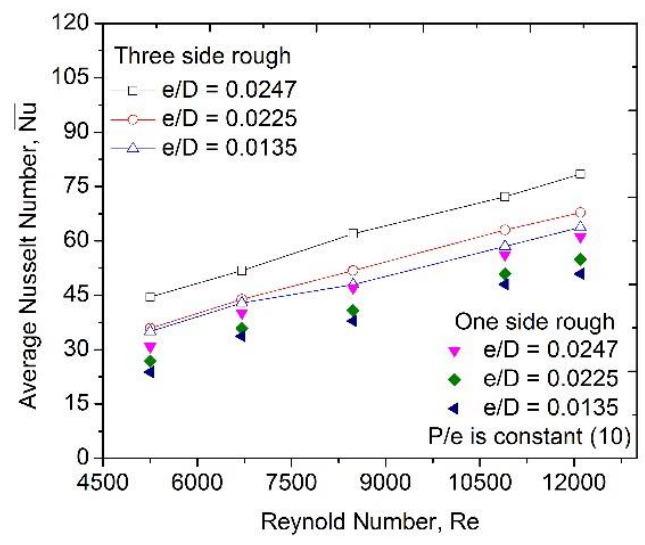

Figure 7. Variation of Nusselt number with Reynold's number for different values of e/D

\subsection{Development of ANN structure}

In the present work, total 50 sets of data were taken from experiments. The proposed MLP NN model to predict the heat transfer of one side and three side roughened absorber plate solar air heater is shown in Figure 8. The neural structure is developed with 3 layers such as input, output and hidden layer in between. At input layer five numbers of parameters such as number of rough surface side $\left(R_{i}\right)$, relative roughness height (e/D), roughness height (e), relative roughness pitch $(P / e)$ and Reynolds number $(\mathrm{Re})$ and one parameter such as average Nusselt number $\overline{N u}$ has been taken in output layer.

In present model 50 input-output data sets were taken. In which 34 data sets were used for training and rest 16 data sets for testing. Feed forward back propagation learning algorithm has been applied for learning of present model.

Before modeling of neural structure, the input and output sample data must be normalized for accuracy of prediction. The following equation has been used to normalize data between -1 and $1[18,20]$.

$$
Y=\left(\text { High }_{\text {value }}-L o w_{\text {value }}\right) \frac{Y_{i}-Y_{\min }}{Y_{\max }-Y_{\min }}+L o w_{\text {value }}
$$

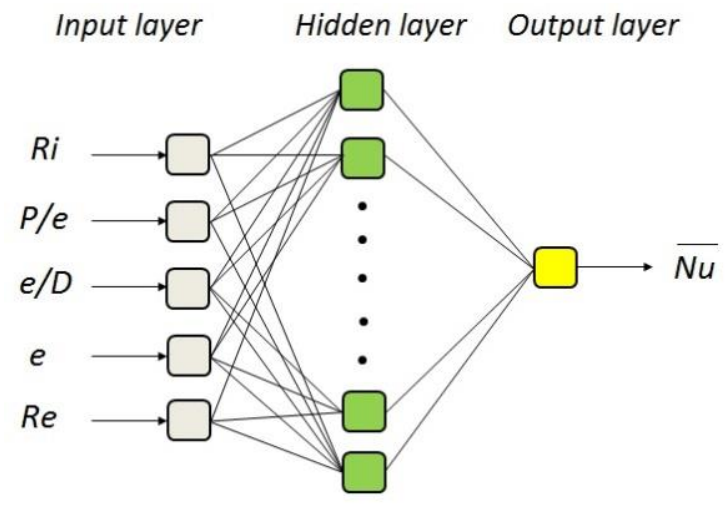

Figure 8. Present study ANN model

In the present study, LM back propagation learning algorithm was used for training process. The number of neurons in hidden layer was estimated by trial and error technique. Using this technique, 6-12 neurons have been selected with single hidden layer. LEARNGDM has been selected, which is adaption learning function, after the selection of training functions. Tansig transfer function was selected for hidden layer and linear function (purelin) for output layer.

\subsection{ANN simulation}

ANN model has been trained by using LM training function with 6-12 neurons in hidden layers. Each neural model was trained for 50 times. This training algorithm adjusts the weights and biases iteratively to minimize the error between actual and predicted values of ANN model. It has been found that LM with 10 neurons is optimum because of lowest error and highest value of $R$. The training performance of different neural model is shown in Table 1. The performance of different models was based on RMSE and R, which is calculated by using Eq. (9) and (10) respectively. From Table 1, it has been found that values of RMSE and R are 0.892026 and 0.99773 respectively for LM10. The weights and biases of optimal ANN model are shown in Table 2.

Table 1. The training performances of different neural model

\begin{tabular}{|c|c|c|}
\hline Number of neurons & RMSE & $\mathrm{R}$ \\
\hline 6 & 1.522865 & 0.99312 \\
\hline 7 & 1.424527 & 0.99411 \\
\hline 8 & 1.377073 & 0.99459 \\
\hline 9 & 0.93691 & 0.99751 \\
\hline $\mathbf{1 0}$ & $\mathbf{0 . 8 9 2 0 2 6}$ & $\mathbf{0 . 9 9 7 7 3}$ \\
\hline 11 & 1.202942 & 0.99513 \\
\hline 12 & 1.280755 & 0.99585 \\
\hline
\end{tabular}

A comparison of the experimental data with predicted data of optimal ANN model with LM-10 is shown in Figure 9 and its error graph is shown in Figure 10. From Figure 10, it has been found that the highest error is 1.6607 at sample-2 1 and lowest error is -2.53048 at sample-14. The stastiscal error analysis results of optimal ANN predicted data are shown in Table 3. From Table 3, in training stage, the value of RMSE, MAE and $R^{2}$ are $0.892025,0.66261$ and 0.99532 respectively. At testing stage, similarly these values are $0.55094,0.31683$ and 0.99790 respectively, which is calculated by Eq. (9), (12) and (13). The formula of mean absolute error and coefficient of determination are as below:

Mean absolute error:

$M A E=\frac{1}{n} \sum_{i=1}^{n}\left(X_{A, i}-X_{P, i}\right)$

Coefficient of determination:

$R^{2}=1-\frac{\sum_{i=1}^{n}\left(X_{A, i}-X_{P, i}\right)^{2}}{\sum_{i=1}^{n} X_{P, i}^{2}}$ 
The regression plot of neural model with LM-10 of training and testing process is shown in Figure 11. From Figure 11, it has been found that value of $\mathrm{R}$ is nearer to unity, which gives the accuracy of performance of the model.

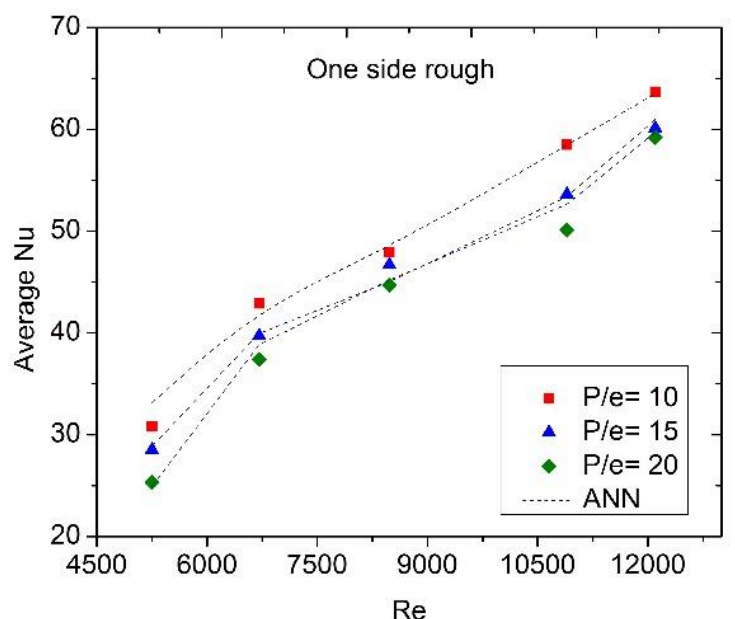

(a)

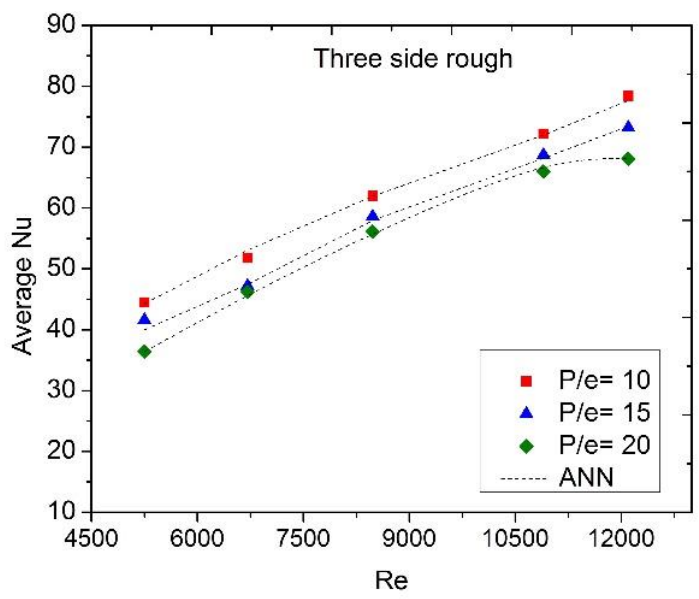

(b)
As from the results of statistical error analysis, it is confirmed that the proposed MLPANN model has been successfully predicted the heat transfer of single and threesided roughened absorber plate solar air heater.

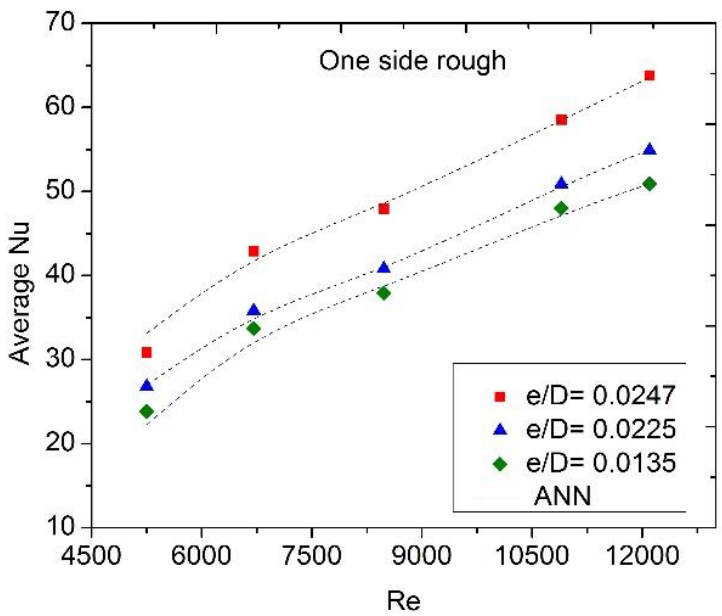

(c)

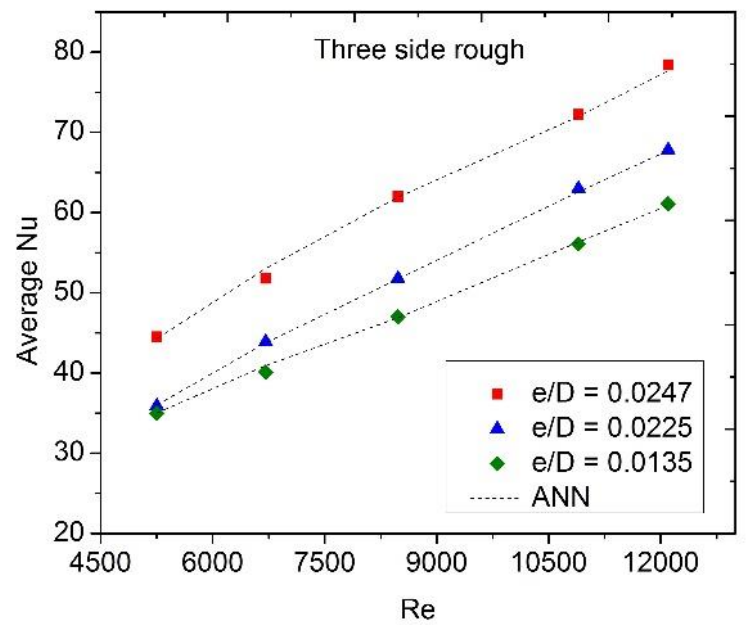

(d)

Figure 9. Comparison of ANN predicted values and experimental data. (a-b) Based on p/e, and (c-d) Based on e/d.

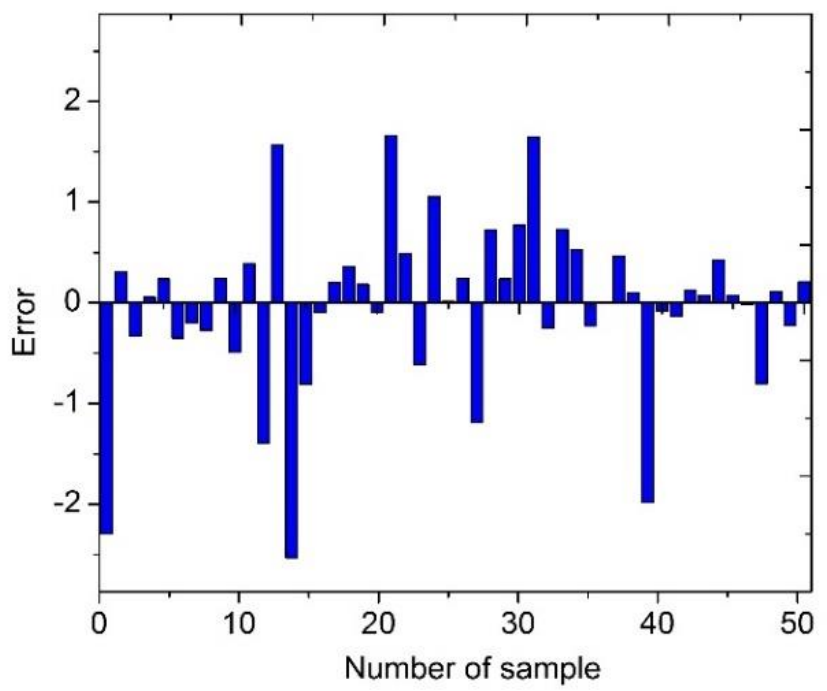

Figure 10. Individual error graph all data samples. 
Table 2. Weights and biases of optimal model

$\begin{array}{cc}0.65618 & -0.8902 \\ -0.70401 & -1.4405 \\ 0.65981 & -0.6002 \\ 0.32211 & -0.5632 \\ -1.13000 & 0.84884 \\ -0.29873 & -0.92699 \\ -0.29012 & 0.61285 \\ -2.6822 & -0.3084 \\ 0.9532 & 0.80315 \\ 0.49385 & 0.9229\end{array}$

$\begin{array}{lll}-0.2041 & 0.1129 & -0.4623\end{array}$

$-2.747$

Weights between input layer and hidden layer ( $W_{10 \times 5)}$ :

0.84696
0.69134
1.0108
-0.18347
1.3169
0.76975
-1.3027
-0.41506
-1.1263
0.79524

$-1.6812$

$-1.4096$

0.58176

0.30708

0.41573

0.36469

0.36529

1.3306

$-0.17833$

$-2.1738$

$-1.2988$

$-0.90957$

0.49732

$-0.8305$

2.3302

$-1.6392$

3.0614

$-0.23192$

Bias in hidden layer $\left(B_{10 x l}\right)$ :

$\begin{array}{lll}1.1654 & -0.0182 & -0.6191\end{array}$

$-0.3746$

$-0.1272$

0.2569

$-0.4994$

Weights in output layer $\left(W_{1 \times 10}\right)$ :

\section{$-2.8423$ \\ 0.3216 \\ 0.5997 \\ Bias in output layer $\left(B_{1 x l}\right)$ :}

0.22509

$-0.7262$

0.87458

$-1.2169$ 0.21892

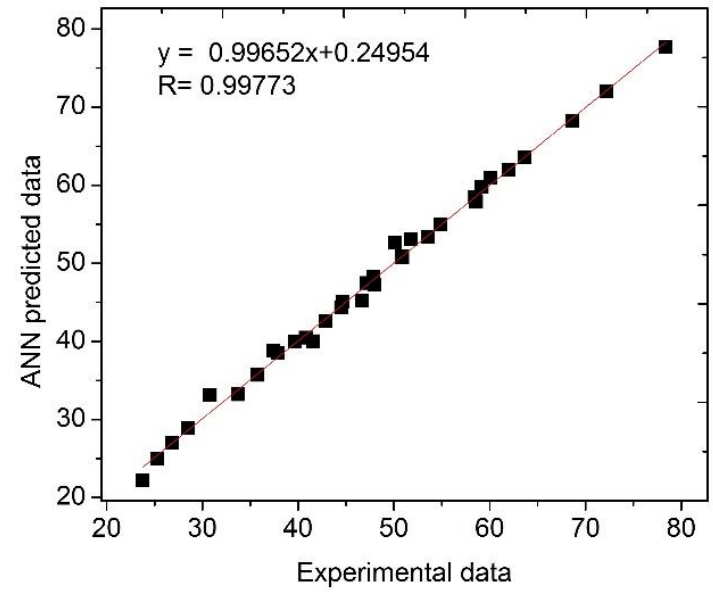

(a)

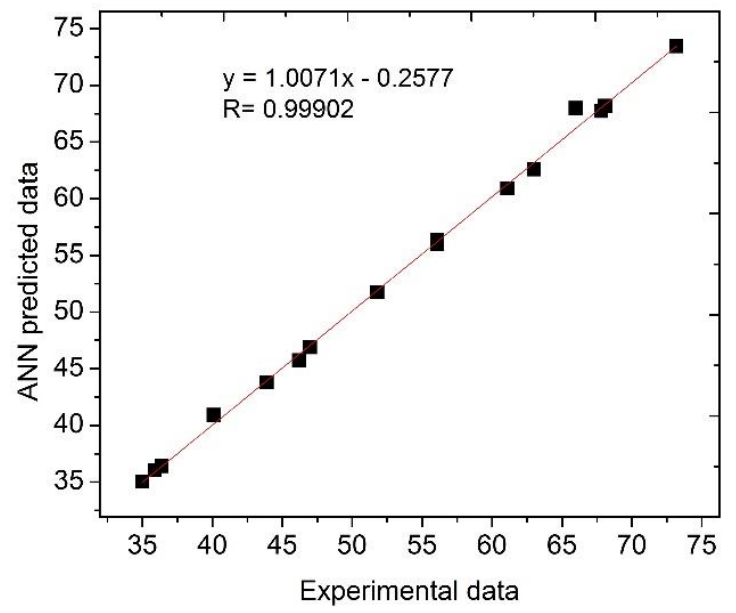

(b)

Figure 11. Regression plot of optimal ANN model predicted results (a) Training data set (b) Testing data set.

Table 3. Statistical performance of proposed MLPNN predicted data.

\begin{tabular}{|c|ccc|ccc|}
\hline \multirow{2}{*}{ Parameter } & \multicolumn{3}{|c|}{ Training } & \multicolumn{3}{c|}{ Testing } \\
\cline { 2 - 7 } & MAE & RMSE & $\mathrm{R}^{2}$ & MAE & RMSE & $\mathrm{R}^{2}$ \\
\hline Average Nusselt number & 0.66261 & 0.892025 & 0.99532 & 0.31683 & 0.55094 & 0.9979 \\
\hline
\end{tabular}

\section{CONCLUSIONS}

In the present work, a MLP neural model has been used to estimate heat transfer characteristic of roughened solar air heater of two different types: one with single side-absorber plate and other with three - sides absorber plate. Total 50 sets of sample data were collected from experiments. Different types of ANN model were developed and trained by taking number of rough surface side, relative roughness pitch, relative roughness height, roughness size and Reynolds number as input variables and Nusselt number as output variable. From 50 set of data, 34 data sets were used for training and 16 data sets for testing. In the present model, LM learning algorithms was used and optimum results were obtained for 10 neurons in the hidden layer. Finally, the 5-101 neural model successfully predicts the heat transfer of SAH. The predicted results were compared with actual data and found that the values of MAE were 0.66261 and 0.31683 , and RMSE were 0.892025 and 0.55094 for testing and training data sets respectively. Similarly, the values of $\mathrm{R}^{2}$ were 0.99532 and 0.9979 respectively. From the above results, the proposed MLP ANN model shows the accuracy of predicted results. This paper provides the information to researchers 
those who are working in the field of heat transfer and using ANN techniques in their works.

\section{ACKNOWLEDGMENT}

The Authors are very thankful to NIT Jamshedpur for providing all the facilities to carry out the research work.

\section{REFERENCES}

[1] Duffie JA, Beckman WA. (1991). Solar Engineering of Thermal Processes, second ed.,Wiley Publication, New York. https://www.wiley.com.

[2] Tiwari GN. (2004). Solar Energy: Fundamentals, Design, Modelling and Applications, Narosa Publishing House, New Delhi, India. https://www.crcpress.com.

[3] Bhushan B, Singh R. (2010). A review on methodology of artificial roughness used in duct of solar air heaters. Energy 35(1): 202-212. https://doi.org/ 10.1016/j.energy.2009.09.010

[4] Chamoli S, Thakur NS, Saini JS. (2012). A review of turbulence promoters used in solar thermal system. Renew. Sustain. Energy Rev. 16(5): 3154-3175. https://doi.org/ 10.1016/j.rser.2012.01.021

[5] Prasad BN. (2013). Thermal performance of artificially roughened solar air heaters. Sol. Energy 91: 59-67. https://doi.org/ 10.1016/j.solener.2013.01.014

[6] Prasad BN, Behura AK, Prasad L. (2014). Fluid flow and heat transfer analysis for heat transfer enhancement in three sided artificially roughened solar air heater. Sol. Energy 105: 27-35. https://doi.org/ 10.1016/j.solener.2014.03.027

[7] Gawande VB, Dhoble AS, Zodpe DB. (2014). Effect of roughness geometries on heat transfer enhancement in solar thermal systems - a review. Renew. Sustain. Energy Rev. 32: 347-378.

https://doi.org/10.1016/j.rser.2014.01.024

[8] Behura AK, Prasad BN, Prasad L. (2016). Heat transfer, friction factor and thermal performance of three sides artificially roughened solar air heaters. Solar Energy 130: 46-59. https://doi.org/ 10.1016/j.solener.2016.02.006

[9] Behura AK, Prasad BN, Prasad L. (2016). Investigation for heat transfer and friction factor characteristic in three sided artificially roughened solar air heater. Ph.D. Thesis, National Institute of Technology, Jamshedpur, Jharkhand, India.

[10] Kalogirou SA. (2000). Applications of artificial neural networks for energy systems. Applied Energy 67 (1-2): 17-35. https://doi.org/ 10.1016/S0306-2619(00)00005-2

[11] Facao J, Varga S, Oliveira AC. (2004). Evaluation of the use of artificial neural networks for the simulation of hybrid solar collectors. International Journal of Green Energy 1(3):337-352. http://dx.doi.org/ 10.1081/GE200033649

[12] Islamoglu Y, Kurt A. (2004). Heat transfer analysis using ANNs with experimental data for air flowing in corrugated channels. International Journal of Heat and Mass Transfer 47: 1361-1365. https://doi.org/ 10.1016/j.ijheatmasstransfer.2003.07.031

[13] Kalogirou SA. (2006). Prediction of flat-plate collector performance parameters using artificial neural networks.

Solar Energy 80: 248-259. https://doi.org/ 10.1016/j.solener.2005.03.003

[14] Sozen A, Menlik T, Unvar S. (2008). Determination of efficiency of flat-plate solar collectors using neural network approach. Expert Syst. Appl. 35(4): 1533-1539. https://doi.org/ 10.1016/j.eswa.2007.08.080

[15] Akdag U, Komur MA, Ozguc AF. (2009). Estimation of heat transfer in oscillating annular flow using artifical neural networks. Advances in Engineering Software 40: 864-870. 10.1016/j.advengsoft.2009.01.010

https://doi.org/

[16] Bopche SB, Tandale MS. (2009). Experimental investigations on heat transfer and frictional characteristics of a turbulator roughened solar air heater duct. International Journal of Heat and Mass Transfer 52: 2834-2848. https://doi.org/ 10.1016/j.ijheatmasstransfer.2008.09.039

[17] Caner M, Gedik E, Kecebas A. (2011). Investigation on thermal performance calculation of two type solar air collectors using artificial neural network. Expert Syst. Appl. 38(3): 1668-1674. https://doi.org/ 10.1016/j.eswa.2010.07.090

[18] Benli H. (2013). Determination of thermal performance calculation of two different types solar air collectors with the use of artificial neural networks. Int. J. of Heat and Mass Transfer 60: 1-7. https://doi.org/ 10.1016/j.ijheatmasstransfer.2012.12.042

[19] Akdag U, Komur MA, Akcay S. (2016). Prediction of heat tranfer on a flat plate subjected to a transversely pulsating jet using artificial neural networks. Applied Thermal Engineering 100: 412-420. https://doi.org/ 10.1016/j.applthermaleng.2016.01.147

[20] Azizi S, Ahmadloo E. (2016). Prediction of heat transfer coefficient during condensation of R134a in inclined tubes using artificial neural network. Applied Thermal Engineering 106: 203-210. https://doi.org/ 10.1016/j.applthermaleng.2016.05.189

[21] Ghritlahre HK, Prasad RK. (2017). Prediction of thermal performance of unidirectional flow porous bed solar air heater with optimal training function using Artificial Neural Network. Energy Procedia 109: $369-$ 376. https://doi.org/ 10.1016/j.egypro.2017.03.033

[22] Haykin S. (1994). Neural Networks, A Comprehensive Foundation, Prentice-Hall, New Jersey.

\section{NOMENCLATURE}

A

ANN

$a_{i}$

$b_{j}$

$B F G$

$C G P$

$C_{d}$

$C_{p}$

$D_{h}$

e

$e / D$

$h$

$k$

$L M$

$m_{f}$

$M A E$
Area of Collector Surface, $\mathrm{m}^{2}$

Artificial Neural Network

Input Variables

Bias

BFGS Quasi-Newton

Polak-Ribiére Conjugate Gradient

Coefficient of discharge

Specific heat of air, $\mathrm{J}^{\mathrm{kg}} \mathrm{kg}^{-1} \cdot \mathrm{K}^{-1}$

Hydraulic Diameter

Roughness height, mm

Relative roughness height

Heat transfer coefficient, $\mathrm{W} . \mathrm{m}^{-2} \cdot \mathrm{K}^{-1}$

Thermal conductivity of air, W. $\mathrm{m}^{-1} \cdot \mathrm{K}^{-1}$

Levenberg-Marquardt

Mass flow rate of air, $\mathrm{kg}$. $\mathrm{s}^{-1}$

Mean Absolute Error 


\begin{tabular}{|c|c|c|c|}
\hline$M L P$ & Multi-Layered Perceptron & $\bar{X}$ & Average value \\
\hline $\mathrm{Nu}$ & Nusselt number & $\mathrm{Y}$ & Experimental value \\
\hline$\Delta P$ & Pressure drop, N. $\mathrm{m}^{-2}$ & & \\
\hline$P / e$ & Relative roughness pitch & Greek letters & \\
\hline$Q_{u}$ & Energy gained by air, $\mathrm{W}$ & & \\
\hline$R$ & Correlation coefficient & $\rho_{a}$ & Density of air, $\mathrm{kg} \cdot \mathrm{m}^{-3}$ \\
\hline$R^{2}$ & Coefficient of determination & $\beta$ & Ratio of orifice diameter to pipe diameter \\
\hline $\begin{array}{l}\text { RMSE } \\
\text { SAH }\end{array}$ & Root mean square error & & \\
\hline $\begin{array}{l}S A H \\
S C G\end{array}$ & Solar Air Heater & Subscripts & \\
\hline$T$ & $\begin{array}{l}\text { Scaled Conjugate Gradient } \\
\text { Temperature, K }\end{array}$ & $f_{O}$ & Outlet air \\
\hline$w_{i j}$ & Weights & $f i$ & Inlet air \\
\hline$X_{A}$ & Actual value & & \\
\hline$X_{P}$ & Predicted value & & \\
\hline
\end{tabular}

